\title{
THE AEROCLIPPER \\ A New Device to Explore Convective Systems and Cyclones
}

by J. P. Duvel, C. Basdevant, H. Bellenger, G. Reverdin, A. Vargas, and J. Vialard

Aeroclipper balloons, designed for taking measurements at the air-sea interface, can withstand extreme conditions encountered when they are drawn

into tropical cyclones and then follow the eye trajectory.

$\mathrm{T}$ he Aeroclipper (Fig. 1) is a new balloon device designed to perform relatively long flights (of up to 30 days) in the surface layer (under $50 \mathrm{~m}$ ) over remote ocean regions. Up to now, most long-lasting balloon measurements in the marine boundary layer have been made using superpressure balloons. These superpressure balloons have a constant volume and are thus supposed to fly at a level of constant density. Superpressure balloons in the boundary layer were first developed to probe local dynamical properties along Lagrangian trajectories. Early experiments used a manually operated radar to follow aluminized tetrahedral balloons (or tetroons) for a few hours (Angell and Pack 1960). These tetroons were found to be suitable Lagrangian tracers at a constant level. They were progressively improved (by adding, e.g., a radar transponder) and contributed to new results on turbulence, diffusion, and transport properties, in particular over urban areas (see Businger et al. 1996 for a review). Superpressure balloons of various shapes are still used in local field experiments. These balloons have a life expectancy of a few hours and require a local receiver system.

In order to study large-scale flows in the marine boundary layer over remote regions, long-lasting balloons tracked by satellite are required. Following the EOLE experiment (Morel and Bandeen 1973), Laboratoire de Meteorologie Dynamique (LMD) and Centre National d'Etudes Spatiales (CNES) decided, in 1975, to develop a version of superpressure balloons adapted to long flights in the tropical marine boundary layer. Many improvements of the balloon envelope and the payload design were necessary to resist the stress inflicted by the lower

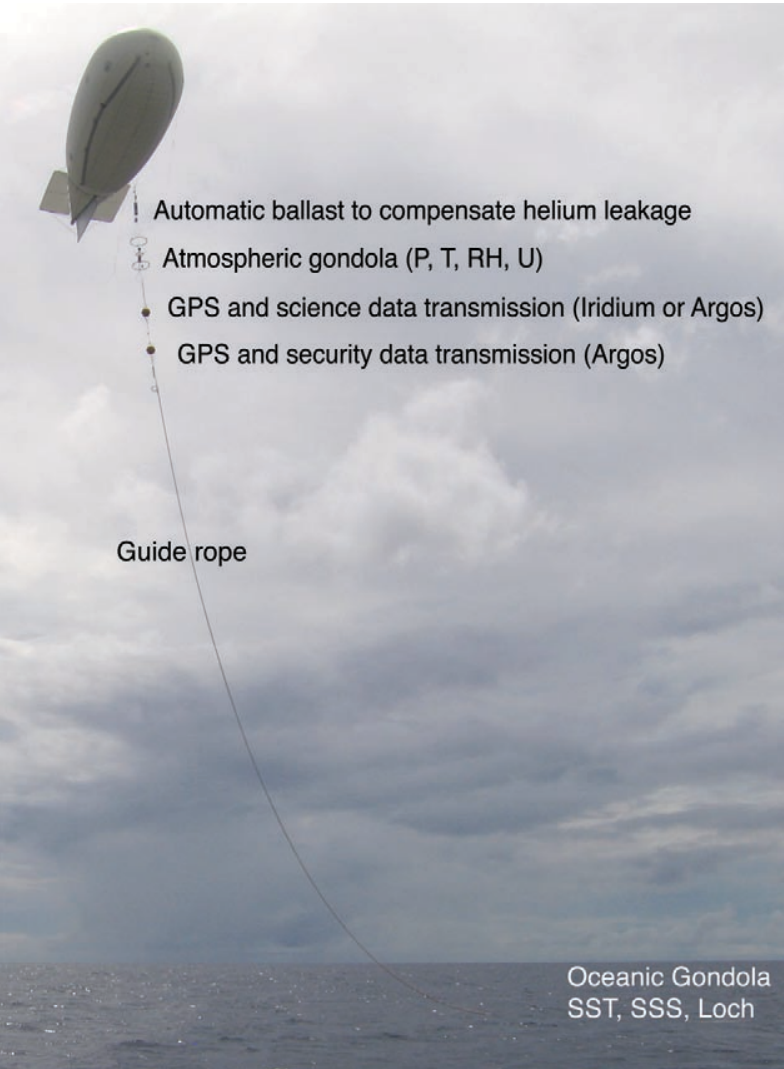

FIG. I. The Aeroclipper measurement system. For the VASCO prototypes, there were two transmission gondolas, one dedicated to science telemetry (using either Argos for Aeroclippers I, 2, 3, and 7, or Iridium for the others) and a security transmission gondola providing a redundancy of the position as well as software for automatic balloon separation in forbidden areas (around the island and continental regions). The length of the guide rope is $50 \mathrm{~m}$ between the ocean gondola and the security transmission gondola. 
tropical atmosphere (Cadet et al. 1975). In particular, a self-enclosed balloon payload was used to protect the electronics during rain or condensation episodes that can force the balloon down to the sea surface. These balloons, carrying pressure, temperature, and moisture devices, were used during the Monsoon Experiment (MONEX) BALSAMINE experiment in 1979 to study dynamical properties of the low-level Indian monsoon jet (Reverdin and Sommeria 1983). During BALSAMINE, 88 balloons, tracked using the newly developed Argos satellite transmission system, were launched in the tropical marine boundary layer (near $900 \mathrm{hPa}$ ) from the Seychelles Islands and from the northern tip of Madagascar (Cadet et al. 1981). Similar balloons, equipped with GPS, but still transmitting data using the Argos system, were later used during the Indian Ocean Experiment (INDOEX) in 1999 (Ethe et al. 2002) and during the Validation of the Aeroclipper System under Convective Occurrences (VASCO) in 2007. During VASCO, some of these balloons were attracted to and destroyed in Tropical Cyclone Dora, and one balloon was captured for around 12 revolutions near the eyewall of Cyclone Gamede with almost no radial speed and a tangential speed of around $35 \mathrm{~m} \mathrm{~s}^{-1}$ (see Vialard et al. 2009).

To correctly interpret measurements taken by a boundary layer balloon in terms of turbulence, diffusion, or transport, it is necessary to maintain a nearly constant flight level. However, such a constant level is difficult to maintain over flights of several days or weeks. The density of the balloon will change due to helium leaks, envelope stretch, or diurnal solar heating. The main problem, however, remains with the condensation and rain that may quickly and drastically modify the mass, and thus the flight level, of the balloon. On many occasions, the resulting

AFFILIATIONS: DuVel, BASDEVANT, AND BellengeR一Laboratoire de Météorologie Dynamique, CNRS, UPMC, ENS, Ecole Polytechnique, Paris, France; ReVERdin AND VIALARD—Laboratoire d'Océanographie Expérimentation et Approches Numériques, CNRS, UPMC, IRD, Paris, France; VARGAS-Centre National d'Etudes Spatiales, Toulouse, France.

CORRESPONDING AUTHOR: Dr. Jean-Philippe Duvel, Laboratoire de Météorologie Dynamique, Ecole Normale Supérieure, 24 rue Lhomond, F-7523I, Paris, CEDEX 05, France E-mail: jpduvel@Imd.ens.fr

The abstract for this article can be found in this issue, following the table of contents.

DOI:10.1175/2008BAMS2500.1

In final form 25 March 2008

(2009 American Meteorological Society water loading forces the balloon down to the sea surface where the atmospheric sensors are damaged. Recently, the National Oceanic and Atmospheric Administration (NOAA)/Air Resources Laboratory Field Research Division (ARLFRD) made an important improvement by incorporating adjustable air ballast into superpressure balloons. The improved control of the balloon altitude was successfully demonstrated for a flight of 12 days above the North Atlantic during the International Consortium for Atmospheric Research on Transport and Transformation (ICARTT) field experiment held in the summer of 2004 (Businger et al. 2006). This is a very promising technique that will most probably become standard for superpressure balloons used to study large-scale dynamics and transport in the tropical boundary layer.

Another way to maintain the altitude of a balloon close to the surface is to use a guide rope floating on the surface of the ocean. This is the principle of the Aeroclipper. Because of the drag of the guide rope on the ocean surface, the Aeroclipper is no longer a Lagrangian tracer of boundary layer circulation. Rather, the Aeroclipper is a moving platform following quasi-Lagrangian trajectories and providing in situ measurements in the atmospheric surface layer and at the surface of the ocean. The guide rope mass deposited on the ocean surface continually compensates for variations in the balloon lift. If the lift of the balloon decreases, the balloon descends and more of the guide rope floats on the ocean surface, reducing the total mass of the balloon-rope system until the equilibrium value is attained. The guide rope keeps the balloon close to the surface and prevents the instrument gondola from dropping into the ocean in case of rain or condensation loading. The Aeroclipper is thus theoretically able to measure low-level dynamics and surface turbulent fluxes for several weeks in remote regions of tropical oceans. Like superpressure balloons in the boundary layer, an Aeroclipper is attracted toward convective regions by the low-level wind convergence generated by the associated low surface pressure. Compared to Eulerian platforms (moored buoys) or to oceanographic ships, these balloons are thus expected to increase atmospheric boundary layer sampling in active convective systems.

During VASCO, two Aeroclippers survived in Tropical Cyclone Dora, enduring wind speeds greater than $40 \mathrm{~m} \mathrm{~s}^{-1}$ and giving continuous estimates of tangential and radial winds as a function of the distance from the eye during the convergence phase. The two Aeroclippers then stayed in the eye of Dora for more than a week and remained in the low pressure center when Dora became an extratropical depression. 
Because of this success in mechanical design, and despite some deficiencies of the present system that require new developments, we think that such a device has good potential for further use, especially for cyclone nowcasting. In this article, we present the scientific objectives of the Aeroclipper, its current design and instrumentation and some preliminary results of the VASCO test experiment, as well as ongoing developments.

SCIENTIFIC OBJECTIVES. Previous observations showed that the surface turbulent fluxes of heat, water vapor, and momentum increase in the vicinity of tropical convective systems. This is due to wind gusts related in part to the convergence generated by convective updrafts and in part to density currents generated by cold convective downdrafts (e.g., Esbensen and McPhaden 1996). The presence of convection then leads to an augmentation of the wind speed at a regional scale. Also, for a grid point of a general circulation model (GCM), the turbulent fluxes should be increased over fluxes computed by the resolved low-level dynamics (e.g. Redelsperger et al. 2000). This is important since the accuracy of surface fluxes in GCMs strongly impacts on the representation of the large-scale circulation, including the monsoons (Miller et al. 1992). This may also impact synoptic-scale waves (e.g., equatorial waves, easterly waves) or intraseasonal (e.g. Madden-Julian) dynamical perturbations associated with organized deep convection (see, e.g. Duvel and Vialard 2007). The flux enhancement will cool the surface during the convective phase of the perturbation, giving a negative feedback on the convective instability that affects the dynamics of the perturbation.

Surface flux intensification related to convection organized at different scales is, however, still a source of uncertainty in current GCMs. The knowledge of the intensity of these flux perturbations is based on a few in situ observations, mainly over the western Pacific warm pool during the Tropical Ocean Global Atmosphere Coupled Ocean-Atmosphere Response Experiment (TOGA COARE) research program. These perturbations were also quantified using mesoscale models (Jabouille et al. 1996). Future experiments using Aeroclippers will aim to complement these studies by significantly increasing the number of observations in the vicinity of mesoscale convective systems.

THE AEROCLIPPER SYSTEM. The Aeroclipper device is a streamlined balloon vertically stabilized by a guide rope (Fig. 1). An atmospheric gondola contains instruments for measuring meteorological parameters (e.g., pressure, temperature, relative humidity, and relative wind speed) and an oceanic gondola contains instruments for sea surface temperature (SST), sea surface salinity (SSS), and the speed with respect to water (Table 1). A GPS position of the Aeroclipper is collected every minute and atmospheric measurements are performed every $10 \mathrm{~s}$ and averaged over $1 \mathrm{~min}$. The speed and the course of the Aeroclipper are computed every minute from two GPS positions at the beginning and at the end of the minute. The wind speed is obtained by adding the speed of the Aeroclipper and the measured relative wind speed during that minute. The wind direction is given by the course of the Aeroclipper (which means that the deviation due to oceanic currents is neglected). The temporal resolution of the transmitted data is 1 or 15 min depending on the transmission system. Iridium and Argos transmission systems were tested during VASCO. The Aeroclipper is designed to provide 30 days of data (limited by battery, helium leakage). Aeroclipper 2 converged into Dora, with wind speeds greater than $45 \mathrm{~m} \mathrm{~s}^{-1}, 12$ days after its deployment and then followed the eye of Dora and the center of the ensuing extratropical depression for more than 17 days, before being voluntarily stopped by destructing the balloon at $45.6^{\circ} \mathrm{S}, 59^{\circ} \mathrm{E}$ (near Kerguelen Island) because the flight duration was limited to 30 days.

For small wind speed, the horizontal aerodynamic drag of the balloon and the hydrodynamic drag of the oceanic gondola result in a displacement speed of about half the wind speed. The resulting relative wind acting on the streamlined balloon gives additional dynamical lift. This lift is necessary to compensate the inclination of the system as the wind increases. For winds larger than a given threshold (typically $12 \mathrm{~m} \mathrm{~s}^{-1}$ for VASCO, but variable depending on the balloon shape and the mass of the suspended guide rope at rest) the oceanic gondola skates over the ocean surface and ocean data are temporarily lost. During VASCO, the oceanic gondola was too fragile and the sensors were destroyed after a few skating episodes. A new oceanic gondola is currently under development. The dynamical lift of the streamlined balloon and the skating of the oceanic gondola during strong wind episodes are mandatory to avoid large and destructive forces on the system.

Previous measurements made by Friehe et al. (1984) and Beardsley et al. (1997) showed that atmospheric parameters measured by an aircraft flying at $30 \mathrm{~m}$ above sea surface can be corrected by bulk algorithms to match quite well with buoy measurements 


\begin{tabular}{|c|c|c|c|c|}
\hline Gondolas & Sensors & Manufacturer & Model & Accuracy \\
\hline \multicolumn{5}{|l|}{ Atmosphere } \\
\hline & Sonic anemometer & Gill & Windsonic & $2 \%$ \\
\hline & Thermometer & & Hygroclip & $0.2 \mathrm{~K}$ \\
\hline & Hygrometer & & S3C03 & $1.5 \%$ \\
\hline & Barometer & Vaisala & PTB210 & $0.3 \mathrm{hPa}$ \\
\hline \multicolumn{5}{|l|}{ Ocean } \\
\hline & Knotmeter & SpeedTech & SM-4A & $0.2 \mathrm{~ms}^{-1}$ \\
\hline & $\begin{array}{l}\text { Temperature } \\
\text { (10-cm depth) }\end{array}$ & Prosensor & PT100 & $0.1 \mathrm{~K}$ \\
\hline & $\begin{array}{l}\text { Temperature- } \\
\text { salinity } \\
\text { (40-cm depth) }\end{array}$ & $\begin{array}{l}\text { Sea \& Sun } \\
\text { Technology }\end{array}$ & & $\begin{array}{l}0.01 \mathrm{~K} \\
0.15 \mathrm{PSU}\end{array}$ \\
\hline
\end{tabular}

TABLE I. Mechanical structure of the gondolas and details on the sensors used during VASCO 2007. For future experiments, the mechanical structure of the atmospheric gondola will be simplified (the gimbal will be removed) and reinforced. The oceanic gondola will be entirely redesigned to support highspeed skating at the ocean surface.

taken at 10 and at $3.5 \mathrm{~m}$. This suggests that, despite the relatively elevated atmospheric instrumentation, Aeroclipper measurements allow surface parameters and the turbulent fluxes of moisture, heat, and momentum to be assessed using a bulk algorithm. Here, we use the COARE 3.0 bulk algorithm of Fairall et al. (2003). One challenge of the Aeroclipper is to obtain the height of the atmospheric gondola. This height varies with the wind that changes the speed of the system, the water and air drags, and the dynamical lift of the balloon. This height also varies as a function of the static balloon lift, which changes slowly because of helium leakage, and rain or condensation on the balloon. For the VASCO experiment, there was no sensor dedicated to the height monitoring. This balloon height is therefore estimated from i) the measurement of the longitudinal force in the guide rope performed just under the security transmission gondola (Fig. 1) and ii) a simple static catenary model of the guide rope. This model computes the suspended mass and the shape of the guide rope from the longitudinal force measurement and the horizontal drag of the balloon deduced from a known penetration coefficient and the measured relative wind. This model was validated against a precise differential GPS height determination during a dedicated test experiment. For time intervals of $1 \mathrm{~min}$, the height accuracy is around $2 \mathrm{~m}$. This error is mainly related to high- frequency oscillations (of around $1 \mathrm{~min}$ ) that result in height perturbations of the order of $5 \mathrm{~m}$ (which can be also verified using the barometer). Using the COARE 3.0 algorithm, one can show that the flux determination from elevated measurements is not very sensitive to the height accuracy. For an average measurement height around $30 \mathrm{~m}$, even a height error of $9 \mathrm{~m}$ results in a negligible error compared to the flux error of around $10 \%$ that results from the instrument accuracy. These results suggest that the accuracy of bulk fluxes computed from Aeroclipper measurements is theoretically similar to the accuracy of bulk fluxes computed from more conventional ship or buoy measurements. This will be verified by dedicated experiments in the near future. Note that the very light mechanical structure of the Aeroclipper reduces wind and thermal perturbations that are an important source of uncertainty for large platforms. The lift of the balloon, and thus of the atmospheric gondola, by strong winds is also beneficial to reduce ocean wave-induced flow distortion.

THE VASCO TEST EXPERIMENT. For the VASCO test campaign, eight Aeroclippers were deployed in the Indian Ocean from Mahé Island International Airport $\left(4.4^{\circ} \mathrm{S}, 55.3^{\circ} \mathrm{E}\right)$ in January 2007. The deployment time of an Aeroclipper is critical, not only to determine the large-scale conditions setting the main measurement sector for the following days, but also to avoid neighboring islands just after deployment. Local weather conditions have to be relatively calm during deployment (although a couple of deployments were successfully made in the rain or with winds greater than $6 \mathrm{~m} \mathrm{~s}^{-1}$ during VASCO). To guide the decision-making process, an ensemble of 50 Aeroclipper trajectories was computed twice a day on the basis of the Ensemble Prediction System (EPS) of the European Centre for Medium-Range Weather Forecasts (ECMWF). This gave a probabilistic approach for the prediction of the Aeroclipper trajectory. A large deviation between trajectories for a 
given day (and also a large change between trajectory ensembles from one day to another) is an indication of a less reliable forecast. Figure 2 shows two trajectory prediction ensembles for two Aeroclippers launched on 24 January and on 7 February 2007. The first ensemble is more homogeneous and in better agreement with the real trajectory of Aeroclipper 4. Aeroclipper 6 moved faster and more southward than the corresponding ensemble forecast. The ensembles give a good indication of the large-scale tendency, but are sometimes relatively far from the actual trajectory. This is due in part to deficiencies of the forecast system and in part to perturbations of the real trajectory by mesoscale circulations that are not represented in the large-scale ECMWF model.

\section{AEROCLIPPER MEASUREMENTS DURING}

VASCO. Among the eight Aeroclippers launched, two were destroyed after only a few hours: Aeroclipper 3 for an unknown reason, perhaps lightning; and Aeroclipper 7 because it struck Coetivy Island (the risk of which had been shown by the forecasted trajectories). Aeroclippers 1 and 2 endured very rough conditions without apparent damage and both lasted for the nominal duration of 30 days. For the other Aeroclippers, the main default was a too fragile mechanical structure most probably due to a different transmission gondola (since this was the only difference compared to Aeroclippers 1 and 2). These Aeroclippers, with atmospheric measurements, lasted between 4 and 11 days and were destroyed either by strong gusts or close to Cyclone Favio.

Some measurements collected with Aeroclipper 4 are used here to illustrate potential scientific applications expected from a more robust mechanical structure and a more appropriate oceanic gondola. The first application is the estimate of surface turbulent flux perturbations due to convective systems. Aeroclipper measurements of wind, temperature, and humidity are done at variable heights in the surface layer. As expected, this height is mostly a function of the surface wind (Fig. 3), with a higher gondola for larger winds because of the dynamical lift of the streamlined balloon. For calm conditions encountered on 25 January in the morning, the low height is most probably due to condensation or rain deposited on the balloon. Using the COARE 3.0 algorithm, we estimate the surface turbulent fluxes (Fig. 4) and project the measured parameters to the 10-m standard level (Fig. 3) for 30-min averages of the initial sampling of $1 \mathrm{~min}$. The Meteorological Satellite (Meteosat) infrared images are also used to trace the presence of high convective cloudiness along the Aeroclipper path (Fig. 3). During the first night and the following morning, there is a series of cold and dry gusts related to convective developments that progressively cool and dry the atmospheric surface layer. The first gusts around midnight are not associated with local high clouds and are thus probably related to the development of shallow convection. The dry and cold air circulating over a warm ocean considerably increases the surface turbulent fluxes of sensible heat, water, and momentum (Fig. 4). This flux enhancement contributes to the surface ocean cooling (Fig. 3) recorded along the Aeroclipper path.

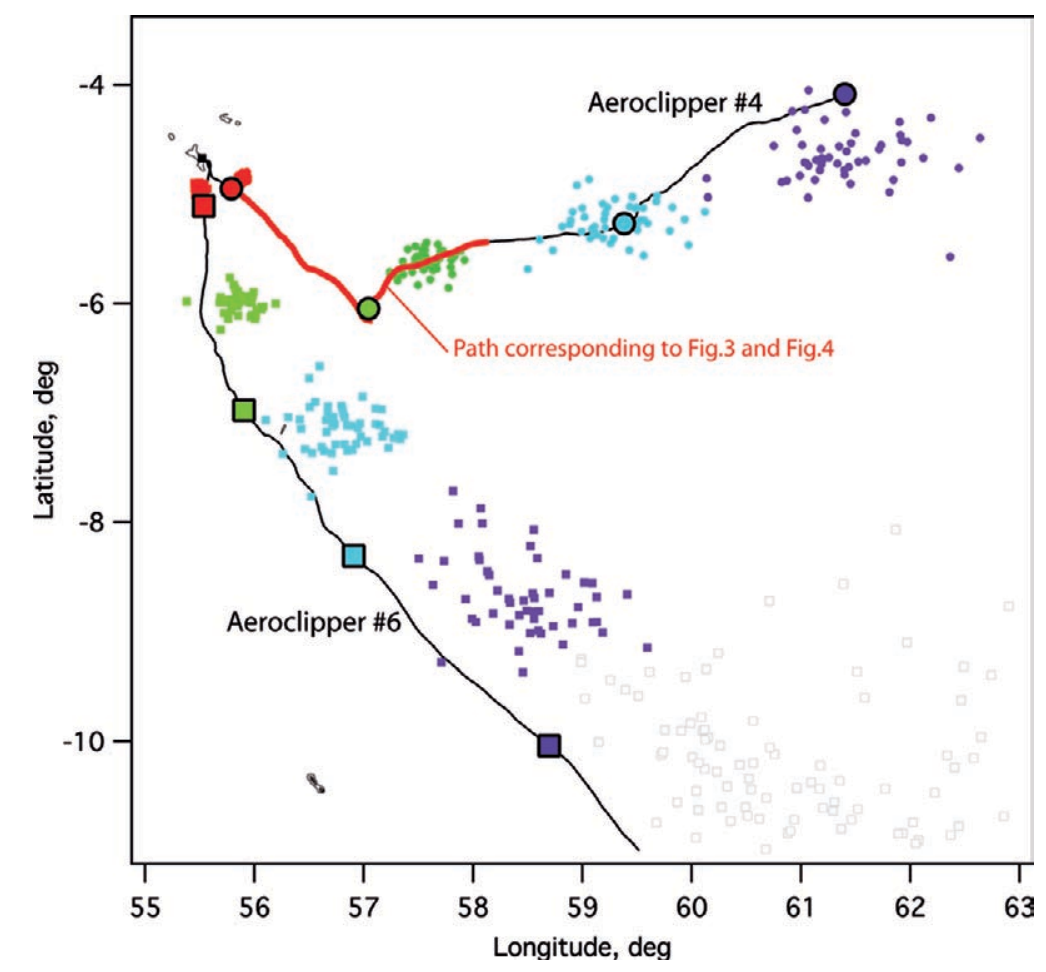

FIG. 2. Ensemble predictions at 12, 36, 60, and $84 \mathrm{~h}$ for simulations starting, respectively, at 0000 GMT 23 Jan (circles, Aeroclipper 4) and at 0000 GMT 6 Feb 2007 (squares, Aeroclipper 6). The predicted position of the Aeroclippers is represented for each day at noon. The real trajectory for each Aeroclipper is also represented (black lines) with large markers at noon for each day. The red part of the trajectory for Aeroclipper 4 corresponds to measurements reported in Fig. 3. 


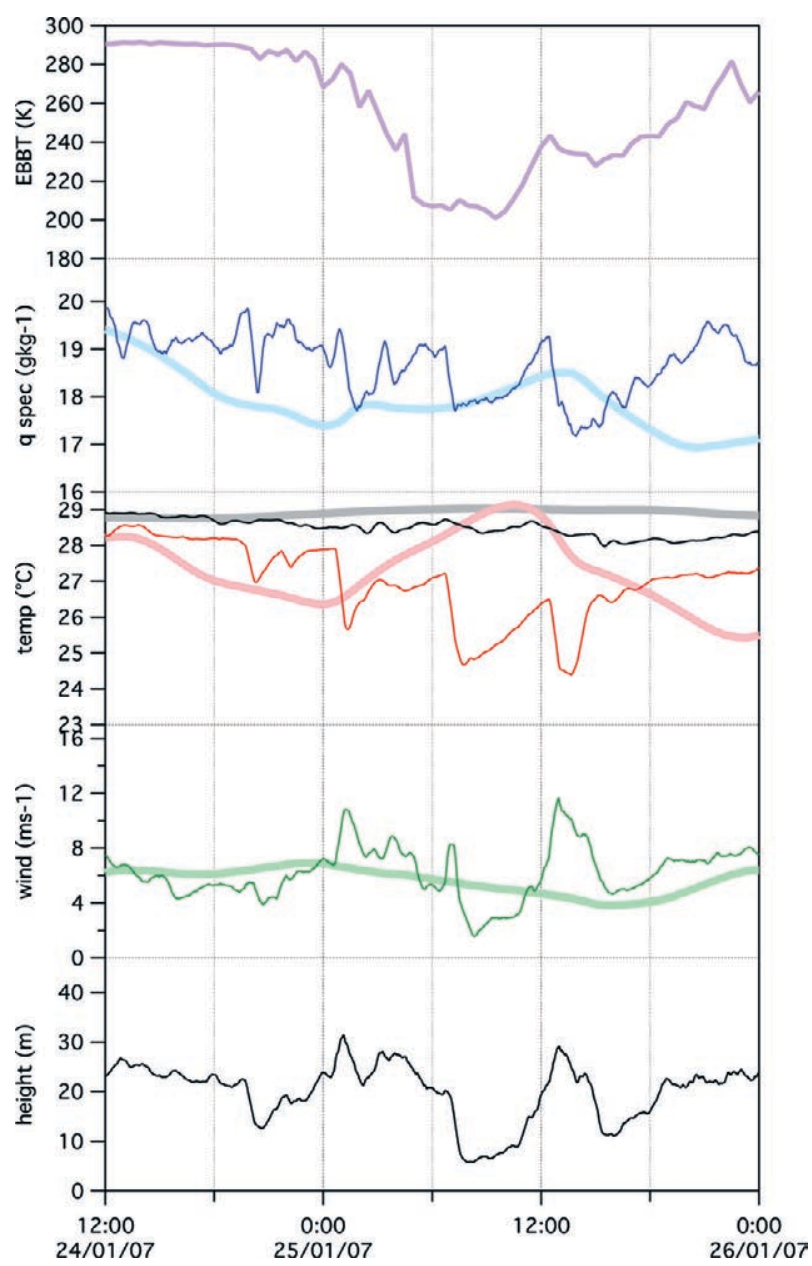

FIG. 3. Time series of Aeroclipper 4 measurements and of Meteosat IR brightness temperature for the red trajectory reported in Fig. 2. (from top to bottom) IR brightness temperature at the top of the atmosphere (purple), I0-m specific humidity (blue), 40-cm ocean temperature (black) and $10-\mathrm{m}$ air temperature (red), I0-m wind (green) deduced from the Aeroclipper displacement and relative wind measurements, and height of the Aeroclipper atmospheric measurements (black). These curves are 30-min running means of the original I-min time step. $\mathbf{3 0} \mathrm{min}$ correspond to a displacement of the Aeroclipper of $3.6 \mathrm{~km}(8.1 \mathrm{~km})$ for a $10-\mathrm{m}$ wind of $5 \mathrm{~m} \mathrm{~s}^{-1}\left(10 \mathrm{~m} \mathrm{~s}^{-1}\right)$. The thick lines represent the ECMWF atmospheric variables at $10 \mathrm{~m}$ and the SST used in the model along the path of the Aeroclipper.

These perturbations are comparable in magnitude to those measured during COARE (e.g., Weller et al. 2004). However, surface winds larger than $10 \mathrm{~m} \mathrm{~s}^{-1}$ were often measured by the Aeroclippers in the Indian Ocean during VASCO, but were hardly sampled in the Pacific during COARE. This is in part due to the different weather regime but may also be attributed to the Aeroclipper measurement system

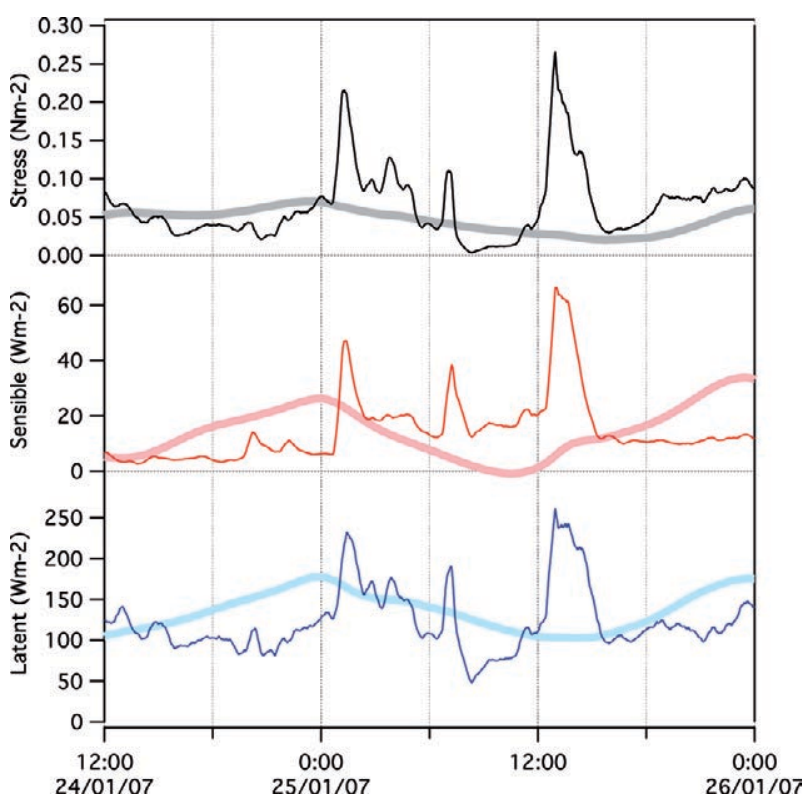

Fig. 4. Surface fluxes computed with the COARE 3.0 bulk algorithm for the time series shown in Fig. 3 with thick lines for ECMWF variables. (from top to bottom) Wind stress (black), turbulent sensible heat flux (red), and turbulent latent heat flux (blue).

itself that tends to converge toward the heart of the mesoscale systems, giving a better sampling of these strong wind episodes.

Aeroclipper measurements may be used to assess the simulated air-sea interaction in global circulation models or in mesoscale models for a variety of meteorological situations. For the example shown in Figs. 3 and 4, the ECMWF gave a correct prediction of the large-scale surface circulation (Fig. 2). However, the meteorological analyses did not describe the convectively perturbed episode (Fig. 3). Rather, the temperature of the atmospheric surface layer follows the daily insolation, resulting in minimum surface turbulent fluxes around noon (Fig. 4). Note also that the satellite-derived SST used for meteorological analyses is too large, except for the clear conditions at the beginning of the series (Fig. 3). This illustrates the fact that a lack of SST infrared satellite measurements under large deep convective events, due to the screening effect of the associated cloudiness, can result in a warm SST bias in the products used to initialize forecasts.

DORA. During VASCO, two Aeroclippers (1 and 2) converged into Tropical Cyclone Dora during its developing stage and remained within the eye of the cyclone the following days (Fig. 5). Both Aeroclippers stayed near the center of the eye for most of the active phase, as for the situation illustrated by the infrared 


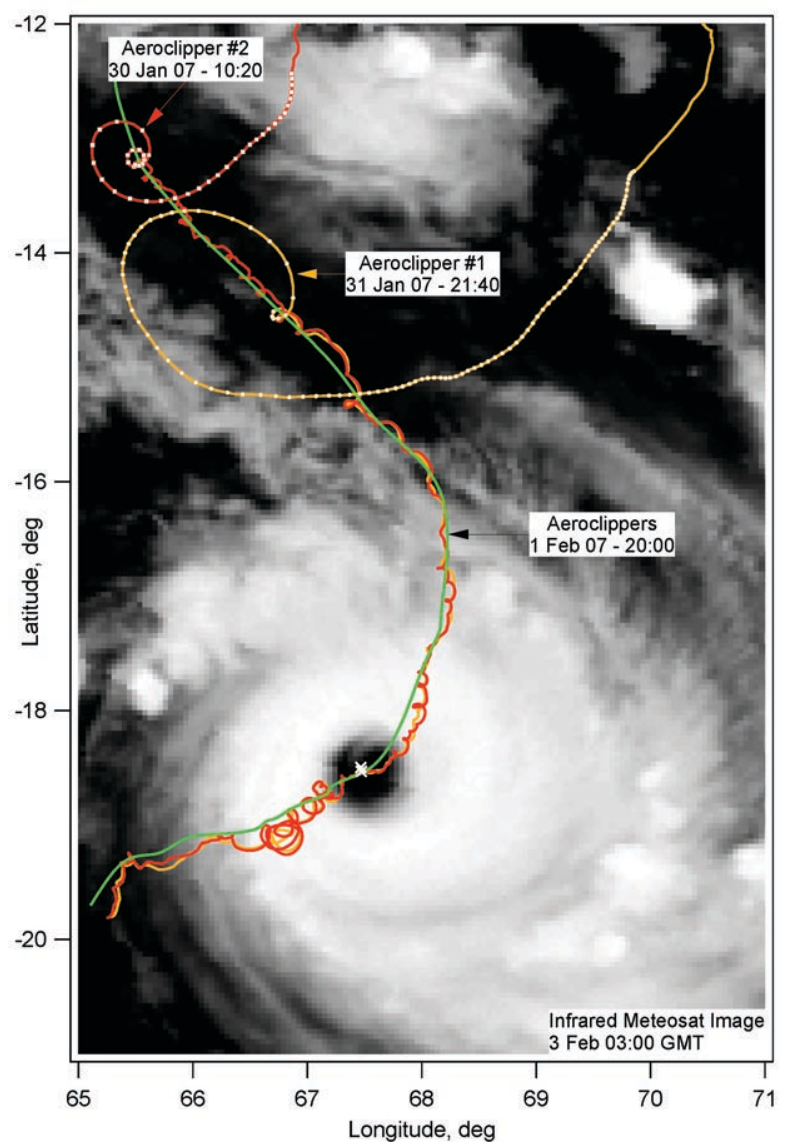

FIG. 5. Trajectories for Aeroclippers I (yellow) and 2 (red) and for the center of Dora (green) between 1200 GMT 29 Jan and 0000 GMT 6 Feb 2007. The trajectory of the center of Dora is a spline curve computed from positions given by La Réunion Tropical Cyclone Centre and slightly adapted using Aeroclipper trajectories. The infrared Meteosat image taken at 0300 GMT 3 Feb 2007 is superimposed and the white crosses represent the position of the two Aeroclippers for this hour. White points on the red and yellow curves show trajectories corresponding to the wind computations reported in Fig. 6.

image in Fig. 5, suggesting surface wind convergence in the eye itself. The Aeroclippers then followed large circles at the edge of the eye a few hours later. Since both Aeroclipper have very similar trajectories, this certainly traces a change in the dynamics of the eye; in particular, for the surface divergence field. The larger circles indeed correspond to the beginning of the weakening phase of Dora after its maximum was reached at 1000 GMT 3 February 2007.

Unfortunately, no atmospheric data were transmitted from these two Aeroclippers during this episode because the onboard software had been accidentally switched to a wrong measurement mode a few days before. We only have the location and the speed of

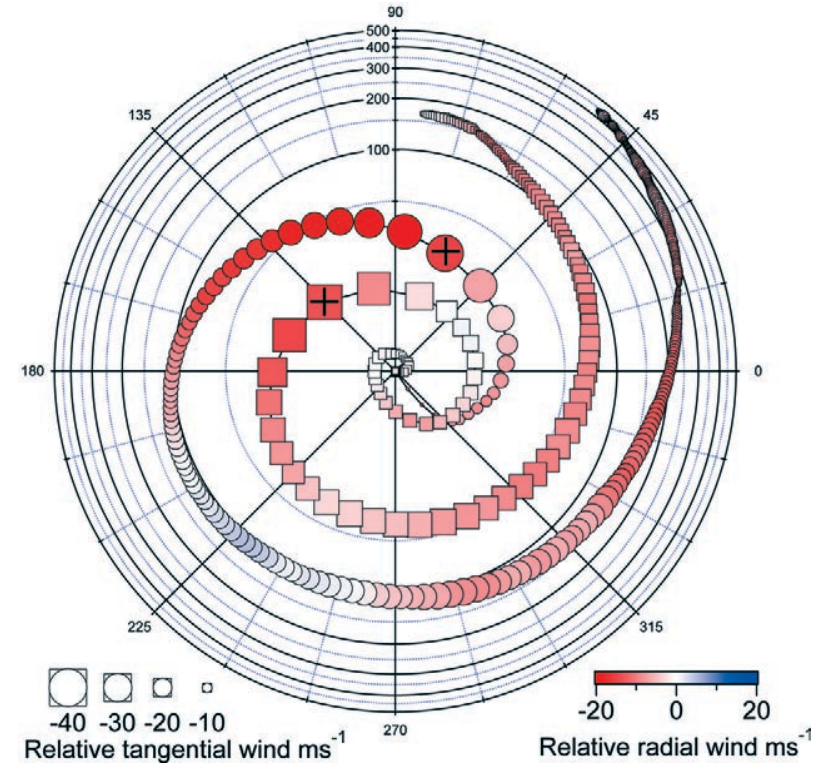

FIG. 6. Relative tangential and radial wind recorded by Aeroclipper I (circle; 2220 GMT 30 Jan-23 10 GMT 3 I Jan 2007) and Aeroclipper 2 (squares; 0250 I330 GMT 30 Jan 2007) as they converged into Dora. The radius of the polar graph represents the distance from the center of Dora (logarithmic scale in $\mathbf{k m}$ ) and the angle represents the position of the Aeroclipper in regard to the moving direction of the center (i.e., zero angle is the course of Dora). The black crosses show the position of the eyewall (i.e., maximum surface wind) at the Aeroclipper crossing time.

these two Aeroclippers. Fortunately, we are able to derive the wind speed as a function of the Aeroclipper speed using relative wind speed measurements taken by Aeroclippers 5 and 6 close to Cyclone Favio with wind speeds larger than $25 \mathrm{~m} \mathrm{~s}^{-1}$. This function is not linear because the dynamical lift of the balloon progressively raises the guide rope. For wind speeds above $\sim 12 \mathrm{~m} \mathrm{~s}^{-1}$, the oceanic gondola skates over the ocean and the relative wind speed tends to converge asymptotically to $\sim 6 \mathrm{~m} \mathrm{~s}^{-1}$. The function is applied to estimate the wind speed encountered by Aeroclippers 1 and 2 and then to compute the tangential and radial winds as a function of the distance from the center of Dora during the entrance phase (Fig. 6). These winds are computed relative to the speed and direction of the displacement of the center of Dora. Aeroclipper 1 experiences a first tangential wind maximum in the right-forward quadrant of the cyclone at around $125 \mathrm{~km}$ from the center. This could be related to an outer eyewall of Dora during its developing stage. The tangential wind then decreases in the right-rear quadrant of the cyclone and the relative radial wind becomes positive (circulation diverging from the center). The strongest convergence and tangential wind phase oc- 
curred in the left quadrants where both Aeroclippers crossed the inner eyewall (maximum surface wind marked with plus signs in Fig. 6). This inner eyewall maximum wind speed is located at around $20 \mathrm{~km}$ from the center at 1015 GMT 30 January $\left(39.4 \mathrm{~m} \mathrm{~s}^{-1}\right.$ for Aeroclipper 2) and at $30 \mathrm{~km}$ from the center at 2145 GMT 31 January (45 $\mathrm{m} \mathrm{s}^{-1}$ for Aeroclipper 1).

FUTURE FIELD EXPERIMENTS. The Aeroclipper provides a new approach to sample the surface layer in remote ocean regions. It can be used to investigate the surface dynamics and thermodynamic perturbations associated with organized convective systems over the tropical oceans. These balloons also have the potential to take measurements at the air-sea interface in tropical cyclones. Staying in the surface layer, they tend to converge toward the center of the cyclone and remain in the eye. As illustrated above by the link between the weakening of Dora and the change of circulation regime of the Aeroclippers, continuous measurements made in the eye of a cyclone and transmitted in near-real time could be used for nowcasting and predicting cyclone evolution. Moreover, surface pressure measurements taken in the eye could validate and improve the accuracy of the Dvorak technique (which estimates cyclone intensity from satellite pictures; see, e.g., Velden et al. 2006), especially for cyclones of the South Indian Ocean where only a few in situ measurements exist. The Aeroclipper is also expected to give interesting measurements of the surface dynamics during the convergence phase in active tropical storms and cyclones, as shown above, but also during the cyclone genesis phase. In particular, combining satellite imagery and Aeroclipper in situ measurements could give information on low-level vortices generated by vorticity convergence into different convective updrafts during the cyclone genesis phase (see, e.g., Montgomery et al. 2006).

Experimental strategies must be developed to take full advantage of the new measurement capabilities of the Aeroclipper. Special care will be given to the choice of the deployment site in order to optimize sampling in regard to the main scientific objectives (convective systems and cyclones). To this end, the Aeroclipper trajectory model will be used to simulate different experimental configurations using the ECMWF EPS. The Aeroclipper system also requires improvements, especially for the robustness of the mechanical structure and of the oceanic gondola. This gondola is currently being redesigned with a structure able to resist high-speed skating over the ocean. Correct SST measurements during these skating episodes will, however, be hard to obtain with in situ sensors. The possibility of adding an infrared sensor (as for the new NOAA smart balloons; Businger et al.2006) to remotely retrieve the SST from the atmospheric gondola is under study. The usefulness of other sensors, such as a compass to verify the direction of the relative wind and a telemeter to verify the height of the measurements, will also be tested. We may expect to see new field experiments with new and operational Aeroclippers in the years to come.

ACKNOWLEDGMENTS. The Aeroclipper is developed jointly by the Centre National d'Etudes Spatiales (CNES), the French space agency, and the Centre National de la Recherche Scientique (CNRS). LMD and LOCEAN are two laboratories of the Institut Pierre-Simon Laplace (IPSL). We cordially thank the Seychelles National Meteorological Service, and especially Selvan Pillay for his invaluable help during the VASCO test experiment. Detailed and constructive comments were provided by three anonymous reviewers.

\section{REFERENCES}

Angell, J. K., and D. H. Pack, 1960: Analysis of some preliminary low-level constant level balloon (Tetroon) flights. Mon. Wea. Rev., 88, 235-248.

Beardsley, R. C., A. G. Enriquez, C. A. Friehe, and C. A. Alessi, 1997: Intercomparison of aircraft and buoy measurements of wind and wind stress during SMILE. J. Atmos. Oceanic Technol., 14, 969-977.

Businger, S., S. Chiswell, W. Ulmer, and R. Johnson, 1996: Balloons as a Lagrangian measurement platform for atmospheric research. J. Geophys. Res., 101 (D2), 4363-4376.

— , R. Johnson, and R. Talbot, 2006: Scientific insights from four generations of Lagrangian smart balloons in atmospheric research. Bull. Amer. Meteor. Soc., 87, 1539-1554.

Cadet, D., H. Ovarlez, and J. Ovarlez, 1975: Superpressure balloon flights in the tropical boundary layer. J. Appl. Meteor., 14, 1478-1484.

— - - - and G. Sommeria, 1981: The BALSAMINE experiment during the Summer MONEX. Bull. Amer. Meteor. Soc., 62, 381-388.

Duvel, J. P., and J. Vialard, 2007: Indo-Pacific sea surface temperature perturbations associated with intraseasonal oscillations of the tropical convection. J. Climate, 20, 3056-3082.

Esbensen, S. K., and M. J. McPhaden, 1996: Enhancement of tropical ocean evaporation and sensible heat flux by atmospheric mesoscale systems. J. Climate, 9, 2307-2325. 
Ethe, C., C. Basdevant, R. Sadourny, K. S. Appu, L. Harenduprakash, P. R. Sarode, and G. Viswanthan, 2002: Air mass motion, temperature, and humidity over the Arabian Sea and western Indian Ocean during the INDOEX intensive phase, as obtained from a set of superpressure drifting balloons. J. Geophys. Res., 107, 8023, doi:10.1029/2001JD001120.

Fairall, C. W., E. F. Bradley, J. E. Hare, A. A. Grachev, and J. B. Edson, 2003: Bulk parameterization of airsea fluxes: Updates and verification for the COARE algorithm. J. Climate, 16, 571-591.

Friehe, C. A., R. C. Beardsley, C. D. Winant, and J. P. Dean, 1984: Intercomparison of aircraft and surface buoy meteorological data during CODE-1. J. Atmos. Oceanic Technol., 1, 79-86.

Jabouille, P., J. L. Redelsperger, and J. P. Lafore, 1996: Modification of surface fluxes by atmospheric convection in the TOGA COARE region. Mon. Wea. Rev., 124, 816-837.

Miller, M. J., A. C. M. Beljaars, and T. N. Palmer, 1992: The sensitivity of the ECMWF model to the parameterization of evaporation from the tropical oceans. J. Climate, 5, 418-434.

Montgomery, M. T., M. E. Nicholls, T. A. Cram, and A. Saunders, 2006: A vertical hot tower route to tropical cyclogenesis. J. Atmos. Sci., 63, 355-386.

Morel, P., and W. Bandeen, 1973: The EOLE experiment: Early results and current objectives. Bull. Amer. Meteor. Soc., 54, 298-306.

Redelsperger, J. L., F. Guichard, and S. Mondon, 2000: A parameterization of mesoscale enhancement of surface fluxes for large-scale models. J. Climate, 13, 402-421.

Reverdin, G., and G. Sommeria, 1983: The dynamical structure of the planetary boundary layer over the Arabian Sea, as deduced from constant-level balloon trajectories. J. Atmos. Sci., 40, 1435-1452.

Velden, C., and Coauthors, 2006: The Dvorak tropical cyclone intensity estimation technique: A satellitebased method that has endured for over 30 years. Bull. Amer. Meteor. Soc., 87, 1195-1210.

Vialard, J., and Coauthors, 2009: CIRENE: Air-sea interactions in the Seychelles-Chagos thermocline ridge region. Bull. Amer. Meteor. Soc., 90, 45-61.

Weller, R. A., F. Bradley, and R. Lukas, 2004: The interface or air-sea flux component of the TOGA Coupled Ocean-Atmosphere Response Experiment and its impact on subsequent air-sea interaction studies. J. Atmos. Oceanic Technol., 21, 223-257. 